\title{
Correction to: Strong phosphorus (P)-zinc (Zn) interactions in a calcareous soil-alfalfa system suggest that rational $P$ fertilization should be considered for $\mathrm{Zn}$ biofortification on Zn-deficient soils and phytoremediation of Zn-contaminated soils
}

\author{
Honghua He $(\mathbb{D} \cdot$ Miaomiao Wu • Rui Su • Zekun Zhang • Chao Chang • Qi Peng • \\ Zhigang Dong • Jiayin Pang • Hans Lambers \\ Published online: 21 April 2021 \\ (C) Springer Nature Switzerland AG 2021
}

\section{Correction to: Plant Soil \\ https://doi.org/10.1007/s11104-020- \\ 04793-w}

The original version of the article unfortunately contain a mistake introduced during the production phase. Tables 3 and 4 are missing in the PDF version of the article. The missing tables have been inserted in the PDF file.

The original article has been corrected.

The online version of the original article can be found at https://doi.org/10.1007/s11104-020-04793-w

H. He $(\bowtie) \cdot$ Z. Dong

State Key Laboratory of Soil Erosion and Dryland Farming on the Loess Plateau, Northwest A\&F University, Yangling 712100

Shaanxi, China

e-mail: honghuahe@ms.iswc.ac.cn

H. He $\cdot \mathrm{M} . \mathrm{Wu} \cdot \mathrm{R} . \mathrm{Su} \cdot \mathrm{Z}$. Zhang $\cdot$ C. Chang

College of Natural Resources and Environment, Northwest A\&F

University, Yangling 712100 Shaanxi, China

H. He $\cdot$ Q. Peng $\cdot$ Z. Dong

Institute of Soil and Water Conservation, Chinese Academy of

Sciences and Ministry of Water Resources, Yangling 712100

Shaanxi, China

H. He $\cdot$ H. Lambers

School of Biological Sciences, The University of Western

Australia, Perth, WA 6001, Australia
Publisher's note Springer Nature remains neutral with regard to jurisdictional claims in published maps and institutional affiliations.

Q. Peng

University of Chinese Academy of Sciences, Beijing 100049, China

J. Pang

UWA School of Agriculture and Environment, The University of Western Australia, Perth, WA 6001, Australia

\section{J. Pang $\cdot$ H. Lambers}

The UWA Institute of Agriculture, The University of Western Australia, Perth, WA 6001, Australia

H. Lambers

Department of Plant Nutrition, China Agricultural University, Beijing 100193, China 